\title{
Commentary: Musical hallucinations: review of treatment effects
}

\author{
Mark D. Griffiths * and Angelica B. Ortiz de Gortari \\ International Gaming Research Unit, Psychology Division, Nottingham Trent University, Nottingham, UK
}

Keywords: musical hallucinations, video games, involuntary musical imagery, Game Transfer Phenomena, involuntary auditory imagery

\section{A commentary on}

Musical hallucinations: review of treatment effects

by Coebergh, J. A. F., Lauw, R. F., Bots, R., Sommer, I. E. C., and Blom, J. D. (2015). Front. Psychol. 6:814. doi: 10.3389/fpsyg.2015.00814

\section{OPEN ACCESS}

Edited by:

Xavier Noel,

Fonds de la Recherche Scientifique-

FNRS, Belgium

Reviewed by:

Adriano Schimmenti,

Kore University of Enna, Italy

Yasser Khazaal,

Geneva University Hospitals,

Switzerland

*Correspondence:

Mark D. Griffiths

mark.griffiths@ntu.ac.uk

Specialty section:

This article was submitted to

Psychopathology,

a section of the journal

Frontiers in Psychology

Received: 15 September 2015 Accepted: 22 November 2015 Published: 09 December 2015

Citation:

Griffiths $M D$ and Ortiz de Gortari $A B$ (2015) Commentary: Musical hallucinations: review of treatment effects. Front. Psychol. 6:1885. doi: 10.3389/fpsyg.2015.01885
According to Coebergh et al. (2015), musical hallucinations (MHs) "are auditory hallucinations characterized by songs, tunes, melodies, harmonics, rhythms, and/or timbres... and that the mechanisms responsible for the mediation of $M H$ are probably diverse" (p. 2). While some scholars have reported that the prevalence rate of MHs among the general population is at present unknown and/or rare (Vitorovic and Biller, 2013), "involuntary musical imagery" [INMI; i.e., a tune that comes into the mind and repeats without unconscious control (Williamson et al., 2012)] is thought to be more commonplace. For instance, $89 \%$ in a Finish sample $(n=12,519)$ reported experiencing it at least once a week (Liikkanen, 2012). Music hallucination prevalence rates among various groups have been reported including obsessive-compulsive disorder patients (41\%; Hermesh, 2004), elderly people with auditory problems (2.5\%; Cole et al., 2002), and general hospital setting patients (0.16\%; Fukunishi et al., 1998). Possible etiological factors include otological factors (e.g., hearing loss), intoxication, brain injury, epilepsy, and psychiatric disorders (Cope and Baguley, 2009; Coebergh et al., 2015).

Although Coebergh and colleagues described MHs, they were not explicitly defined. In other reviews, Woo et al. (2014) defined MHs as "complex auditory perceptions in the absence of an external acoustic stimulus and are often consistent with previous listening experience" (p. 1) whereas Vitorovic and Biller (2013) noted that MHs "represent a specific form of auditory hallucinations whereby patients experience formed songs, instrumental music, or tunes, without an external musical stimulus" (p. 1). Williams (2015) provided a classification of INMI and noted they cover a number of different types of involuntary musical experience (including MHs). Despite the lack of detailed definition, it is known that MHs occur within the context of an individual's culture and are often viewed by those experiencing them as intrusive and sometimes unpleasant (Cope and Baguley, 2009; Vitorovic and Biller, 2013).

As far as the present authors are aware, no review paper examining musical hallucinations has ever included papers referring to musical hallucinations arising from playing video games. The earliest report in the psychological literature is by Spence (1993) who reported the case of a 20 -yearold female patient with a family history of psychosis. She presented with persecutory delusions, suicidal ideation, violent behavior, and third-person auditory hallucinations comprising $48 \mathrm{~h}$ of constant MHs from the Mario Bros videogame that developed into delusional thoughts. No drugs were found in her urinary system and her EEG was normal when MHs occurred. The MHs from the videogame decreased within $48 \mathrm{~h}$ of treatment (via antidepressants/neuroleptics). 
More recently, a series of papers by the present authors examined Game Transfer Phenomena (GTP). GTP research has demonstrated how the videogame can keep on playing even after the game has been turned off. GTP are nonvolitional phenomena (e.g., altered perceptions, automatic mental processes, and involuntary behaviors) (Ortiz de Gortari and Griffiths, 2015). Analysis of over 1,600 gamers' self-reports have shown that videogame playing can lead to (i) perceptual distortions of physical objects, environments, and/or sounds, (ii) misperceptions of objects and sounds that are similar to those in the videogame, (iii) interpretation of events in real life contexts that utilize the logic of the videogame, (iv) ghost perceptions and sensations of images, sounds, and tactile experiences, and (v) involuntary actions and behaviors based on experiences from the videogame (Ortiz de Gortari et al., 2011, 2015; Ortiz de Gortari and Griffiths, 2014a,b,c, 2015).

One study (Ortiz de Gortari and Griffiths, 2014b) specifically examined auditory GTP experiences. Gamers' experiences identified as GTP in one or more modalities (e.g., visual, auditory) were collected from 60 online videogame forums over 7 months. Of these, there were 192 auditory experiences from 155 gamers collected. The largest numbers of experiences (90\%) were identified as involuntary auditory imagery. This manifested as hearing music $(n=73)$, sound $(n=83)$, or voices from within the game $(n=12)$. Some experiences were triggered by external cues associated with the videogame, while others were not. Experiences with music included hearing high pitch music in addition to calm and classical music.

Music from the videogames was usually experienced persistently, while sound effects or voices appeared to occur more episodically. Hearing the music persistently provoked sleep deprivation, annoyance, and uncertainty. When the music was re-experienced very vividly, the gamers attributed them to external sources associated with the videogame. More specifically, when auditory cues were associated with adverse videogame content, they resulted in such things as hearing sounds coming from objects around them or hearing their own inner speech in a videogame character's voice (Ortiz de

\section{REFERENCES}

Coebergh, J. A. F., Lauw, R. F., Bots, R., Sommer, I. E. C., and Blom, J. D. (2015). Musical hallucinations: review of treatment effects. Front. Psychol. 6:814. doi: 10.3389/fpsyg.2015.00814

Cole, M. G., Dowson, L., Dendukuri, N., and Belzile, E. (2002). The prevalence and phenomenology of auditory hallucinations among elderly subjects attending an audiology clinic. Int. J. Geriatr. Psychiatry 17, 444-452. doi: 10.1002/ gps.618

Cope, T. E., and Baguley, D. M. (2009). Is musical hallucination an otological phenomenon? A review of the literature. Clin. Otolaryngol. 34, 423-430. doi: 10.1111/j.1749-4486.2009.02013.x

Fukunishi, I., Horikawa, N., and Onai, H. (1998). Prevalence rate of musical hallucinations in a general hospital setting. Psychosomatics 39, 175. doi: 10.1016/S0033-3182(98)71368-4

Gardner, M. P. (1985). Mood states and consumer behavior: a critical review. J. Consum. Res. 12, 281-300. doi: 10.1086/208516

Gerra, G., Zaimovic, A., Franchini, D., Palladino, M., Giucastro, G., Reali, N., et al. (1998). Neuroendocrine responses of healthy volunteers to 'techno-music':
Gortari and Griffiths, 2014a). In many cases, the gamers said that they had been playing intensively (i.e., either playing long sessions or playing frequently). Previous studies have linked hearing music in absence of auditory stimuli with the recent or repeated exposure to music (e.g., Gardner, 1985; Gerra et al., 1998; Hyman et al., 2012). One gamer said that he heard the sound of music coming out from the speakers so he stood up to check them, while another heard music from Pokémon when vacuuming. It also appears that musical hallucinations can cross sensory modalities. For instance, some gamers have reported hearing music while seeing images from the videogame (Ortiz de Gortari and Griffiths, 2014a). An online survey about GTP with a convenience sample of 2,362 gamers found that hearing music from videogames when not playing were the more prevalent $(74 \%)$ than hearing sounds $(65.0 \%)$ or voices $(46 \%)$ when not playing (Ortiz de Gortari and Griffiths, Unpublished manuscript).

Based on what is known empirically, we would conclude that (i) $\mathrm{MHs}$ from videogame playing-although not well documented-appear to be relatively commonplace among gamers, and prevalence appears to be higher than found in other populations, (ii) individual interpretation of $\mathrm{MHs}$ from videogames are influenced by the meanings and uses of auditory cues in the videogames, (iii) MHs can manifest beyond one sensory modality and have been reported acrosssensory channels (e.g., hearing music while seeing ghost images from the game), (iv) those researching in the field of MHs and INMI appear to have overlooked the literature on these phenomena related to videogame playing, (v) better definitions and further research are needed for MHs, and a distinction between MHs and INMI is required, as etiological issues have not been systematically studied among video game players.

\section{AUTHOR CONTRIBUTIONS}

MG thought of the idea for the paper and wrote the first draft of the paper. AO then added material to the draft. Both authors then edited the paper down. relationships with personality traits and emotional state. Int. J. Psychophysiol. 28, 99-111. doi: 10.1016/S0167-8760(97)00071-8

Hermesh, H. (2004). Musical hallucinations: prevalence in psychotic and nonpsychotic outpatients. J. Clin. Psychiatry 65, 191-197. doi: 10.4088/JCP.v65n0208

Hyman, I. E., Burland, N. K., Duskin, H. M., Cook, M. C., Roy, C. M., McGrath, J. C., et al. (2012). Going gaga: investigating, creating, and manipulating the song stuck in my head. Appl. Cogn. Psychol. 27, 204-215. doi: 10.1002/acp.2897

Liikkanen, L. A. (2012). Musical activities predispose to involuntary musical imagery. Psychol. Music 40, 236-256. doi: 10.1177/0305735611406578

Ortiz de Gortari, A. B., Aronsson, K., and Griffiths, M. D. (2011). Game Transfer Phenomena in video game playing: a qualitative interview study. Int. J. Cyber Behav. Psychol. Learn. 1, 15-33. doi: 10.4018/ijcbpl.2011070102

Ortiz de Gortari, A. B., and Griffiths, M. D. (2014a). Auditory experiences in Game Transfer Phenomena: an empirical self-report study. Int. J. Cyber Behav. Psychol. Learn. 4, 59-75. doi: 10.4018/ijcbpl.2014010105

Ortiz de Gortari, A. B., and Griffiths, M. D. (2014b). Altered visual perception in Game Transfer Phenomena: an empirical self-report study. Int. J. Hum. Comput. Interact. 30, 95-105. doi: 10.1080/10447318.2013.839900 
Ortiz de Gortari, A. B., and Griffiths, M. D. (2014c). Automatic mental processes, automatic actions and behaviours in Game Transfer Phenomena: an empirical self-report study using online forum data. Int. J. Ment. Health Addict. 12, 432-452. doi: 10.1007/s11469-014-9476-3

Ortiz de Gortari, A. B., and Griffiths, M. D. (2015). Game Transfer Phenomena and its associated factors: an exploratory empirical online survey study. Comput. Human Behav. 51, 195-202. doi: 10.1016/j.chb.2015. 04.060

Ortiz de Gortari, A. B., Pontes, H. M., and Griffiths, M. D. (2015). The Game Transfer Phenomena Scale: an instrument for investigating the non-volitional effects of video game playing. Cyberpsychol. Behav. Soc. Netw. 18, 588-593. doi: $10.1089 /$ cyber.2015.0221

Spence, S. A. (1993). Nintendo hallucinations: a new phenomenological entity. Ir. J. Psychol. Med. 10, 98-99.

Vitorovic, D., and Biller, J. (2013). Musical hallucinations and forgotten tunes-case report and brief literature review. Front. Neurol. 4:109. doi: $10.3389 /$ fneur.2013.00109

Williams, T. I. (2015). The classification of involuntary musical imagery: the case for earworms. Psychomusicology 25, 5-13. doi: 10.1037/pmu0000082
Williamson, V. J., Jilka, S. R., Fry, J., Finkel, S., Müllensiefen, D., and Stewart, L. (2012). How do "earworms" start? Classifying the everyday circumstances of involuntary musical imagery. Psychol. Music 40, 259-284. doi: $10.1177 / 0305735611418553$

Woo, P. Y. M., Leung, L. N. Y., Cheng, S. T. M., and Chan, K.-Y. (2014). Monoaural musical hallucinations caused by a thalamocortical auditory radiation infarct: a case report. J. Med. Case Rep. 8:400. doi: 10.1186/1752-19478-400

Conflict of Interest Statement: The authors declare that the research was conducted in the absence of any commercial or financial relationships that could be construed as a potential conflict of interest.

Copyright (c) 2015 Griffiths and Ortiz de Gortari. This is an open-access article distributed under the terms of the Creative Commons Attribution License (CC BY). The use, distribution or reproduction in other forums is permitted, provided the original author(s) or licensor are credited and that the original publication in this journal is cited, in accordance with accepted academic practice. No use, distribution or reproduction is permitted which does not comply with these terms. 